\title{
Editor comment on: Effects of predator presence and habitat complexity on reef fish communities in the Bahamas by Hensel, E, Allgeier, JE, Layman, CA (2019)
}

\author{
Denis Goulet ${ }^{1}$
}

Received: 3 September 2019 / Accepted: 13 September 2019 / Published online: 30 September 2019

(c) Springer-Verlag GmbH Germany, part of Springer Nature 2019

Coral reefs are very complex ecosystems that support a tremendous amount of biodiversity and are often considered the rainforests of the sea. Regrettably, coral reefs have been subjected to numerous stressors leading to a global degradation of these large ecosystems. Specifically, overexploitation of large predatory species and habitat destruction contribute to coral reef attrition (Dulvy et al. 2004; Lee 2006). Although the effects of these two stressors are often investigated separately, removal of large piscivores and habitat destruction are intertwined. The study by Hensel et al. (2019) stands out since the authors conducted an in situ manipulative experiment to simultaneously examine the interaction and effect of predators and habitat quality on coral reef fish abundance and community structure. In the backreef environment on Great Abaco Island, Bahamas, the authors introduced artificial reef structures, of different complexities, and manipulated the presence of the predatory fish, the Nassau grouper. After 60 days, the highly complex reef structures with predators present had up to a $300 \%$ increase in fish abundance compared to all the other treatments. Furthermore, fish species richness was higher in the more complex habitat. Although on the surface, one might expect that predator presence would lower fish abundance, there was in fact an additive effect of predator presence and increased habitat complexity on biodiversity. Furthermore, the positive effect of predator presence and habitat complexity on fish abundance could provide nutrients to promote coral growth and survivorship, which could increase reef complexity and thus further increase fish abundance (Huntington et al. 2017). From a fisheries management and coral reef conservation perspective, this study shows that removal of top predators and reef degradation alter fish densities and species richness. As stated by Hensel et al. (2019) future management practices should consider both conservation of predatory fish and rehabilitating reef complexity.

\section{References}

Dulvy NK, Freckleton RP, Polunin NVC (2004) Coral reef cascades and the indirect effects of predator removal by exploitation. Ecol Lett 7:410-416. https://doi.org/10.1111/j.1461-0248.2004.00593.x

Hensel E, Allgeier JE, Layman CA (2019) Effects of predator presence and habitat complexity on reef fish communities in The Bahamas. Mar Biol. https://doi.org/10.1007/s00227-019-3568-3

Huntington BE, Miller MW, Pausch R, Richter L (2017) Facilitation in Caribbean coral reefs: high densities of staghorn coral foster greater coral condition and reef fish composition. Oecologia 184:247-257. https://doi.org/10.1007/s00442-017-3859-7

Lee SC (2006) Habitat complexity and consumer-mediated positive feedbacks on a Caribbean coral reef. Oikos 112:442-447. https:// doi.org/10.1111/j.0030-1299.2006.14247.x

Publisher's Note Springer Nature remains neutral with regard to jurisdictional claims in published maps and institutional affiliations.

Responsible Editor: U. Sommer.

Denis Goulet

dgoulet@olemiss.edu

1 Department of Biology, University of Mississippi,

University, MS, USA 